\title{
QUALITY CONTROL IN THE CONSTRUCTION OF REINFORCED CONCRETE BUILDINGS IN DAR ES SALAAM
}

\author{
I. A. Rubaratuka \\ Department of Structural Engineering, University of Dar Es Salaam \\ P. O. Box 35131, Dar Es Salaam \\ E-mail: rignas1@uccmail.co.tz
}

\begin{abstract}
Quality Control in the construction industry is very important to ensure that what is being done conforms to the applicable standards or good practice and the contract documents. In this article, results of investigations conducted at different construction sites for reinforced concrete buildings in Dar es Salaam to check if quality control measures are being implemented are discussed. It has been established that generally quality control is not properly carried out. Finally, measures to enhance quality control on sites are outlined.
\end{abstract}

Keywords: Quality control, reinforced concrete, life cycle - cost, curing, strength

\section{$1.0 \quad$ INTRODUCTION}

Reinforced concrete has been and is till one of the most used building materials in the construction of buildings in Dar es Salaam. Reinforced concrete buildings in Dar es Salaam are subjected to severe environmental conditions such as ocean breezes, which have very serious negative influence on their durability and hence their service life.

Although developments in materials and their performance have widened the scope for use of reinforced concrete, still they have also affected its properties particularly in the long term. This indicates clearly that quality control, which is of vital importance for the building industry, needs special attention in its application to reinforced concrete buildings. It has to be noted that lack of quality control during the design and construction stages, are among the causes of failure of reinforced concrete structures (Bungey, 1989).

An efficient design of a reinforced concrete building requires an economical selection of materials, which are properly proportioned and arranged to carry the required loads without developing stresses in excess of the allowable working stresses. In addition, the constructed reinforced concrete buildings have to withstand aggressive environmental conditions.

A properly designed reinforced concrete building need to be well constructed and subsequently regularly maintained. In Dar es Salaam, a number of reinforced concrete buildings show signs of distress in their early ages(Rubaratuka and Mulungu, 1999). Therefore, in order to establish the causes of this problem, an investigation of quality control during the design and construction stages of reinforced concrete buildings in Dar es Salaam has been carried out and the results are presented in this paper.

\subsection{REINFORCED CONCRETE}

Reinforced concrete is concrete in which reinforcement in the form of steel bars, or fibres have been incorporated to strengthen the naturally brittle concrete. In turn, concrete is a composite building material made from a combination of aggregate and cement binder. The most common form of concrete used in Dar es Salaam is a mixture of Portland cement, fine aggregate (sand), coarse aggregate and water. Depending on the requirements of the building, these components are mixed in specific ratios to achieve the desired quality and design specifications.

After mixing and placement of concrete, cement hydrates gluing the other components together and eventually creating a stone-like material. During hydration and hardening, concrete needs to develop certain physical and chemical properties, among others, mechanical strength, low permeability to ingress of moisture, and chemical and volume stability.

Concrete has relatively high compressive strength, but significantly lower tensile strength of about one-tenth of the compressive strength. As a result, concrete may fail from tensile stresses even when loaded in compression. The practical implication of these facts is that concrete elements that are subjected to tensile stresses must be reinforced. 


\subsection{QUALITY CONTROL}

The main objectives of quality control in the construction industry is to ensure the constructed buildings or structures result in satisfactory strength, serviceability and long term durability so as to lower the overall life-cycle cost. Good quality concrete, therefore, provides long service life, lower annual maintenance costs, fire resistance, reduced bacterial growth, easy to clean surface, increased durability of surfaces that are resistant to cracking, abrasion, scaling, acids and other harsh environments and environmental compliance.

As a process, quality control in the construction industry relates to setting specific standards for construction performance, usually through working drawings and specifications; measuring variances from the standards, which is known as quality assurance. Quality assurance in construction also relates to proper architectural and structural design, use of good materials and components, proper workmanship in the execution of works by the contractor and sub contractor, and ultimately proper care during the use of the buildings and timely maintenance and repair by the owner.

Both quality control and assurance involve quality audit of both the inputs as well as the outputs. Inputs are in the form of materials for concrete and steel, workmanship in all stages of batching, mixing, transportation, placing, compaction and curing resulting in the output in the form of reinforced concrete structure/building. Although quality control is the responsibility of each party involved in the construction project, but the contractor has to ensure that the quality of materials and workmanship is as per the specifications, drawings and the relevant codes of practices.

\subsection{QUALITY OF CONCRETE}

Quality of concrete is mainly influenced by the quality of ingredients, water/cement ratio, operations of mixing, placement and curing.

\subsection{Quality of ingredients}

It has to be remembered that good concrete is made of cement, water and aggregate and that poor concrete is made of the same materials. The difference lies in the grading of the aggregate, the portioning of the mix and care with which vital operations of placing, finishing and curing are carried out. Therefore, aggregates, sand and water to be used must satisfy the design specifications. Aggregates must be clean, free from dust and of required strength.

\subsection{Water/Cement ratio}

The water/cement ratio $(\mathrm{w} / \mathrm{c})$ is the ratio by weight of the water to cement in a concrete mixture. Water/cement ratio is an important factor in determining the strength and permeable properties of concrete.

Table 1. Exposure vs water/cement ratio and minimum 28 day compressive strength(Johnson, 2006).

\begin{tabular}{|l|l|c|c|}
\hline $\begin{array}{l}\text { Class of } \\
\text { Concrete }\end{array}$ & \multicolumn{1}{|c|}{ Use } & $\begin{array}{l}\text { Maximum } \\
\text { w/c }\end{array}$ & $\begin{array}{l}\text { Minimum 28 day } \\
\text { Compressive } \\
\text { Strength, Mpa }\end{array}$ \\
\hline $\mathrm{C}-1$ & Severe exposure(silos, floor slabs, etc ) & 0.4 & 35 \\
\hline $\mathrm{C}-2$ & $\begin{array}{l}\text { Normal exposure (floors, wall, beams, } \\
\text { foundations) }\end{array}$ & 0.45 & 32 \\
\hline $\mathrm{N}$ & Mild exposure(footings) & 0.55 & 25 \\
\hline
\end{tabular}

The effect of water/cement ratio on the compressive strength of concrete is shown in Figure 1. From Figure 1, it is clearly shown that compressive strength improves with lower $\mathrm{w} / \mathrm{c}$ ratio. If excess water is used in making concrete, the resulting mixture has more space between the particles of the concrete mixture than can be filled by the cement gel. This results in a weaker, more porous and less durable concrete that may not be able to withstand the exposure for which it was designed. Water permeability for concrete increases exponentially when concrete has a w/c ratio greater than 0.5 . Concrete with lower permeability is desired. In Dar es Salaam, the ratio should be slightly lower than 0.5 for severe exposures and most applications and can be slightly higher for mild exposure as shown in Table 1. 


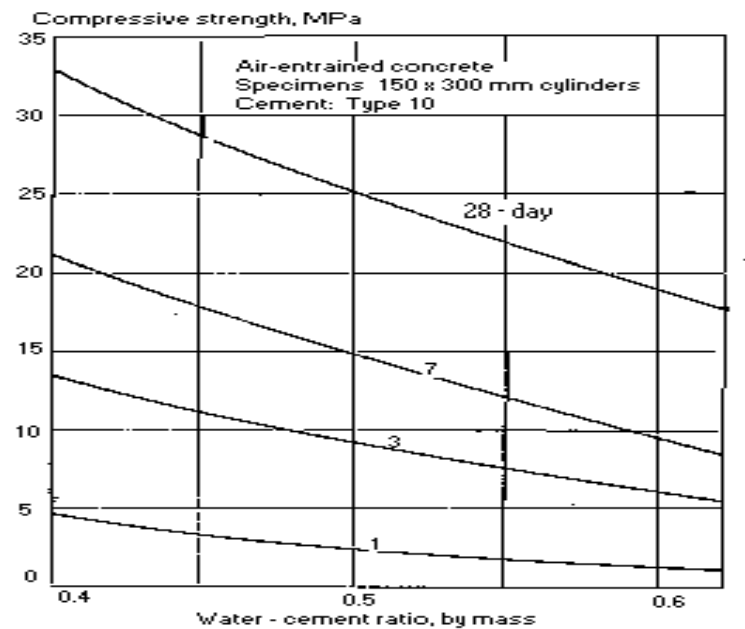

Figure 1. Compressive strength of concrete versus water/cement ratio(Johnson, 2006)

\subsection{Operations of mixing}

\subsubsection{Mixing time}

An optimum mixing time is important in order to produce a homogenous concrete of uniform strength. If mixing takes place over a long period, evaporation of water from concrete mix can take place hence reducing the workability. According to existing standards, the recommended optimum time is two minutes.

\subsubsection{Slump}

Slump test measures the workability of concrete. According to BS1881; Part 2 of 1985, the recommended slump should range between $3-6$ $\mathrm{cm}$.

\subsection{Placement for concrete}

Concrete should be "placed" and not "poured". Concrete can not flow around formwork or over the ground and, therefore, it is to be placed within one metre of its final position in the work. By doing this, separation of the paste from the aggregates is less likely. Placing of concrete is the process of transferring of fresh concrete from the mixing or conveying device to its final place in the forms. The method of placing should be such that segregation, displacement of forms, or of reinforcement in the forms are avoided. Prior to placing loose rustmust be removed from the reinforcement, forms must be cleaned, and hardened surfaces of previous concrete must be cleaned and treated appropriately.

Concrete placed in forms should be compacted or vibrated to achieve a dense product with minimum permeability that is free of air pockets. This procedure increases the strength and durability of concrete, and allows excellent bonding to reinforced steel, joints and water stops. Concrete placed in slabs requires leveling, floating and texturing as part of the placement process. If concrete can be placed, consolidated and finished without undue effort, it is said to be workable. The workability of concrete can be increased by the addition of water, but this is not a desirable method unless the cement content is also increased to maintain the correct water/cementing material ratio. Instead, chemical admixtures can be mixed in to increase the workability without the use of water.

\subsection{Curing}

One of the most important stages in the formation of concrete is curing, which is basically a continuation of hydration. Proper curing of concrete has a very important influence on the final properties of hardened concrete such as durability, strength, water tightness, abrasion resistance, volume stability, etc. Curing is a process of maintaining the temperature and humidity conditions so that the cement hydration reaction can take place. Water must be continually available to the cement particles for hydration to continue. This continuing hydration will cause the concrete to become stronger, less porous and more durable. When moisture is no longer available, hydration stops.

Figure 2 shows the relative strengths of identical concrete cured for different periods of time. Concrete that has moist-cured for 7 days has reached $75 \%$ of its rated strength and achieves $100 \%$ strength by the end of 180 days. By comparison, concrete cured for 3 days attains only $80 \%$ strength and uncured concrete attains only $55 \%$ of its rated strength.

To maintain moisture, concrete need to be covered with plastic or spray-on curing compounds need to 
be applied. These vapour barriers retain water in the concrete by preventing evaporation. On level surfaces, water has to be added by sprinkling or ponding, or by adding coverings such as waterproof films, damp sand, wet burlap or straw. On formed concrete, leaving the forms on helps contain moisture in the concrete.
To properly cure concrete, the temperature must also be controlled. The optimum temperature is $15^{\circ}$ $\mathrm{C}$ with the upper limit of $32^{\circ} \mathrm{C}$ and the lower limit being $4^{0} \mathrm{C}$.

At high temperatures, apply cool water to keep the concrete cool. In cold weather, keep the concrete warm by using insulation, heated forms or heated enclosures.

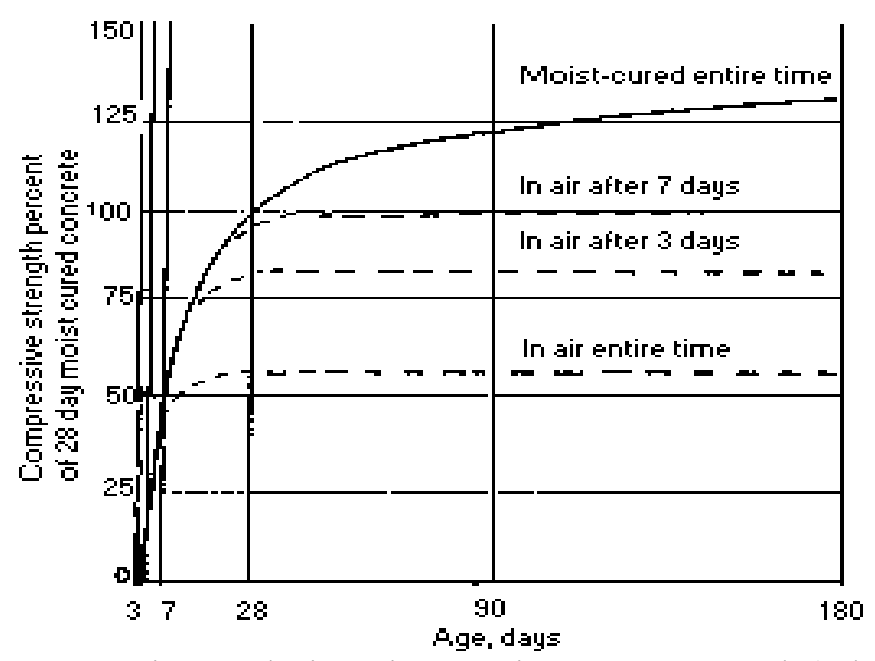

Figure 2. Proper curing results in an increase in concrete strength (Johnson, 2006).

\subsection{Quality of reinforced concrete in Dar es Salaam}

Investigation carried out on different construction sites in Dar es Salaam have revealed the following to be the main causes of unsatisfactory quality of reinforced concrete at most of the sites.

(i) Lack of qualified and experienced technical staff and proper supervision;

(ii) Design deficiencies.

(iii) Poor workmanship;

(iv) Use of improper materials;

\subsection{Lack of qualified and experienced technical staff and proper supervision}

Investigations carried out at different sites in Dar es Salaam revealed that most of the construction sites were being supervised by technicians and foremen instead of engineers. Most of these technicians did not have even adequate site supervision experience.

Lack of qualified and experienced technical staff resulted in inadequate site supervision and consequently to unsatisfactory concrete quality on a number of sites as shown in Figure 3. For example, out of eight sites visited, it was established that quality control measures were being implemented properly only at three sites.

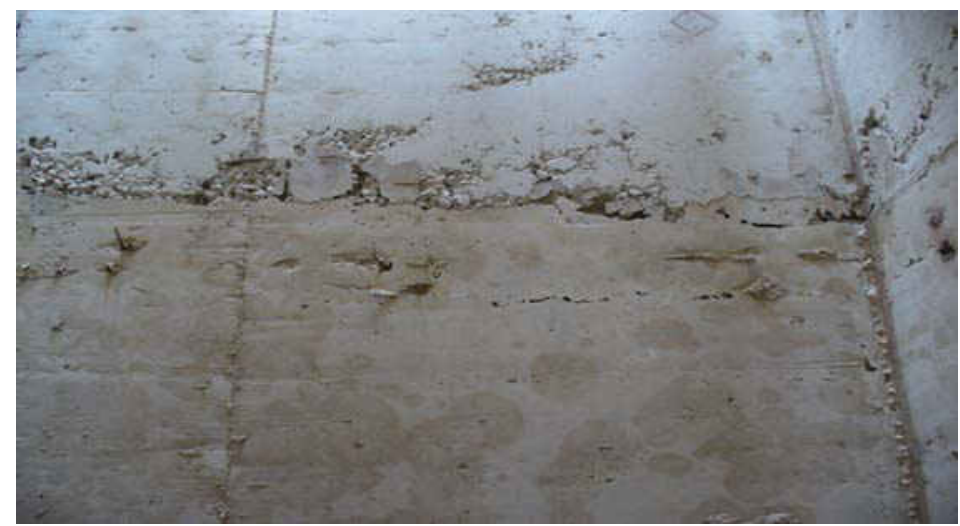

Figure 3. State of reinforced concrete shear wall at one of the sites. 
ven the storage of materials such as sand and aggregates is not properly carried out at most of the sites as shown in Figure 4.

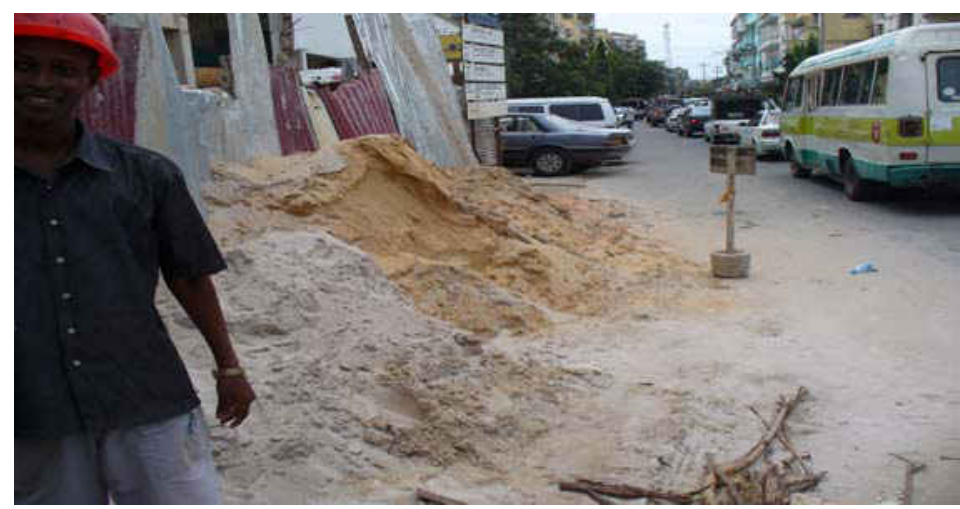

Figure 4. Stored sand and aggregates at one of the sites

\subsection{Design deficiencies}

Investigation carried out in Dar es Salaam at different sites established that most of the design drawings are not properly detailed i.e. inadequate details of beam to column connections, lack of expansion joints where required hence resulting into cracks in buildings, lack of foundations beams where required, etc. (Kalenga, 2005). Further, it was observed that some of the designs are modified or improved during construction hence resulting in additional financial implications, time extensions and inadequate material specifications. This shows that designs are not properly carried out at the precontract stage and even not properly checked during construction. It is not ruled out that, there may be some design deficiencies that are not noticed during construction hence not corrected at all and hence resulting in structural deficient structures.

\subsection{Poor workmanship}

Attention and care during construction of reinforced concrete buildings is crucial to their long term durability. Building codes give guidance appropriate to exposure conditions, mix design(particularly the water/cement ratio) compaction, concrete cover, etc. However, this has not always been the case and the following were observed.

\subsubsection{Mixing}

Mixing of substantial volumes of concrete at some of the sites was being carried out by manual means (without concrete mixers) and in some cases where concrete mixers are used, the duration for mixing is less than the recommended two minutes (see Table 2). In all these cases, concrete was noted to be not homogeneous which can lead to variable strength. At some sites, water/cement ratio was not being adhered to as water was added at the will of concreters. Slump test results were not good as shown in Table 2.

Table 2. Mixing time, slump and compressive strength (after 28 days) tests results

\begin{tabular}{|l|c|l|l|l|c|c|}
\hline No. & Site identi-fication & $\begin{array}{l}\text { Contractors } \\
\text { Class }\end{array}$ & $\begin{array}{l}\text { Mixing } \\
\text { Time } \\
\text { (secs) }\end{array}$ & $\begin{array}{l}\text { Slump } \\
\text { Test } \\
(\mathbf{c m})\end{array}$ & $\begin{array}{l}\text { Design } \\
\text { Strength } \\
\left(\mathbf{N} / \mathbf{m m}^{2}\right)\end{array}$ & $\begin{array}{l}\text { Attained } \\
\text { Strength } \\
\left(\mathbf{N} / \mathbf{m m}^{2}\right)\end{array}$ \\
\hline 1 & S1 & I & 1.5 & 2.9 & 30 & 40 \\
\hline 2 & S2 & I & 2.2 & 4.0 & 30 & 33 \\
\hline 3 & S3 & I & 2.0 & 3.5 & 25 & 19.3 \\
\hline 4 & S4 & V & 2.3 & 5.5 & 30 & 22 \\
\hline 5 & S5 & I & 1.4 & 5.0 & 40 & 32.6 \\
\hline 6 & S6 & V & 2.0 & 6.0 & 25 & 18 \\
\hline 7 & S7 & IV & 2.0 & 4.0 & 30 & 26 \\
\hline
\end{tabular}

\subsubsection{Placement}

Investigations carried out revealed that at some of the sites concrete was being poured instead of being placed, and it was noted that concrete compaction/vibration was being carried out using timber pieces. However, on other sites, compaction /vibration equipment were being used.

Poor compaction at some of the sites resulted in voids, excessively permeable concrete, 
honeycombing, localized reinforcement corrosion and non uniformity in concrete as shown in Figure 3 .

\subsubsection{Curing}

Despite its importance as far as reinforced concrete is concerned, unfortunately curing is the most abused aspect of the construction process. It was observed that curing was not being properly undertaken (not controlled) and in some cases, formwork was stripped off prematurely. This normally result in cracking and hence increased permeability and poor durability.

\subsection{Materials}

The quality and properties of concrete depend on the quantity and proportions of the ingredients used in the mix and the control exercised during various operations starting from the grading and mixing of aggregates to placement in formwork, compacting and curing. Therefore, lack of knowledge about the importance of careful selection and specification of materials may result in poor quality concrete.

During the investigation, the following problems were noted at some sites:

(i) The amount of cement was not as specified i.e. in some cases cement content was too low and in other cases too high hence resulting in weakened and poor durability concrete, and excessive shrinkage; poor workability and cracking.

(ii) Poor quality aggregates (inadequate strength, poorly shaped, badly graded, dusty aggregates as shown in Figure 4, etc.) were being used which normally result in alkaliaggregate reaction, poor workability of concrete, poor compaction, high drying, shrinkage and weak concrete.

(iii) Incorrect water/cement ratios

At some construction sites, incorrect water/cement ratios were observed giving rise to weak concrete, loss of durability, increased permeability to gases and chloride ions. It was further, observed that water used at some sites was very dirty and this normally results into weak concrete. Compressive strength tests results for cubes from different sites are shown in Table 2. The compressive strength intended was attained at two sites out of seven sites investigated. (iv) Most of the contractors were not performing the necessary quality control tests for materials. About $35 \%$ of the contractors (mostly class I, II \& III) on sites were found to be undertaking quality control tests for construction materials (Kalenga, 2005).

\subsection{CONCLUSIONS AND RECOMMENDATIONS}

\subsection{Conclusions}

In view of the investigations carried out at selected sites, it has been established that implementation of quality control measures at most of the sites in Dar es Salaam generally is not carried out. As a result, in most cases, the strength of concrete produced is below the design strength. Most of the contractors were not engaging qualified and experienced staff both to construct and to supervise construction works. In addition, very few contractors were performing quality control tests.

Further, it has been established that the involvement of Municipal Engineers/Inspectors in inspecting, monitoring and checking construction sites is not adequate.

\subsection{Recommendations}

Based on the above observations and conclusions, the following are recommended:

(i) Building designs must be carried out, checked and approved by qualified and experienced technical staff. Further, construction works must be supervised by qualified engineers to ensure that the works are executed properly and quality is controlled;

(ii) Contractors must engage qualified, experienced and competent artisans, technicians and engineers to ensure that the works are executed in accordance to the approved specifications;

(iii) Municipal Councils or responsible local authority organs should enhance the inspection, checking and monitoring of the construction sites to ensure that the works are carried out as per specifications;

(iv) In order to achieve the required properties for ardened concrete (completed structure) such as adequate durability, strength and desired finish, concrete should be sufficiently workable. 


\section{REFERENCES}

Bungey, J. H., (1989), Testing of concrete structures Surey University Press/Chapman and Hall, Glasgow.

BS1881 Testing of Concrete; Part 2, 1983.

BS 8110 Structural use of concrete; Part 1: 1985 Code of Practice for design and Construction.

Jackson, N., and Dhir, R., (1996), Civil Engineering Materials. Macmillan Press Ltd., London.
Johnson, J., (2006), Quality Concrete on the farm. Order No. 04 - 021, Ministry of Agriculture Food and Rural Affairs. Ontario, Canada 2006.

Kalenga, L. H., (2005), Quality assurance and control in the construction of reinforced concrete buildings. Fourth year Final Project, University of Dar es Salaam, Dar es Salaam,

Rubaratuka, I. A., and Mulungu, D., (1999), Defects in reinforced concrete due to environmental Conditions, and concrete treatment: A case study at the University of Dar es Salaam. Uhandisi Journal vol. 23.1., pp. $25-30$. 